\title{
Interferon regulatory factor 4 as a therapeutic target in adult T-cell leukemia lymphoma
}

\author{
Daniel A. Rauch ${ }^{1 \dagger}$, Sydney L. Olson ${ }^{1 \dagger}$, John C. Harding ${ }^{1}$, Hemalatha Sundaramoorthi ${ }^{1}$, Youngsoo Kim², \\ Tianyuan Zhou ${ }^{2}$, A. Robert MacLeod ${ }^{2}$, Grant Challen ${ }^{1}$ and Lee Ratner ${ }^{1 *}$ (D)
}

\begin{abstract}
Background: Adult T-cell leukemia lymphoma (ATLL) is a chemotherapy-resistant malignancy with a median survival of less than one year that will afflict between one hundred thousand and one million individuals worldwide who are currently infected with human T-cell leukemia virus type 1. Recurrent somatic mutations in host genes have exposed the T-cell receptor pathway through nuclear factor $\mathrm{kB}$ to interferon regulatory factor 4 (IRF4) as an essential driver for this malignancy. We sought to determine if IRF4 represents a therapeutic target for ATLL and to identify downstream effectors and biomarkers of IRF4 signaling in vivo.

Results: ATLL cell lines, particularly Tax viral oncoprotein-negative cell lines, that most closely resemble ATLL in humans, were sensitive to dose- and time-dependent inhibition by a next-generation class of IRF4 antisense oligonucleotides (ASOs) that employ constrained ethyl residues that mediate RNase H-dependent RNA degradation. ATLL cell lines were also sensitive to lenalidomide, which repressed IRF4 expression. Both ASOs and lenalidomide inhibited ATLL proliferation in vitro and in vivo. To identify biomarkers of IRF4-mediated CD4 + T-cell expansion in vivo, transcriptomic analysis identified several genes that encode key regulators of ATLL, including interleukin 2 receptor subunits $a$ and $\beta$, KIT ligand, cytotoxic T-lymphocyte-associated protein 4 , and thymocyte selection-associated high mobility group protein TOX 2 .
\end{abstract}

Conclusions: These data support the pursuit of IRF4 as a therapeutic target in ATLL with the use of either ASOs or lenalidomide.

Keywords: HTLV-1, ATLL, IRF4, Lenalidomide, ASO

\section{Background}

Adult T-cell leukemia lymphoma (ATLL) is an incurable, chemotherapy-resistant human malignancy that will afflict approximately $5 \%$ of the 20 million people infected with human T-cell leukemia virus type 1 (HTLV-1) [1]. In the U.S, ATLL disproportionately affects minorities

\footnotetext{
*Correspondence: Iratner@wustl.edu

†Daniel A. Rauch and Sydney L. Olson contributed equally

${ }^{1}$ Division of Oncology, Department of Medicine, Washington University

in St. Louis, 660 S Euclid Ave, Box 8069, St Louis, MO 63110, USA

Full list of author information is available at the end of the article
}

of Native American, Caribbean, African, and Asian heritage [2]. ATLL is derived from CD25+CADM1+T regulatory (Treg) cells and is characterized by blood and bone marrow involvement, hypercalcemia, and lytic bone lesions [3]. Clinical classifications of ATLL include four subtypes: a smoldering subtype with rash and minimal blood involvement, a chronic subtype with higher levels of blood involvement, a lymphoma subtype with lymph node involvement, and an acute subtype with visceral disease, hypercalcemia, and/or elevated lactate dehydrogenase (LDH) [4]. The latter two, more aggressive and lethal subtypes account for the majority of cases. Median

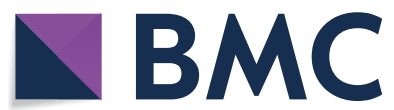

(c) The Author(s) 2020. This article is licensed under a Creative Commons Attribution 4.0 International License, which permits use, sharing, adaptation, distribution and reproduction in any medium or format, as long as you give appropriate credit to the original author(s) and the source, provide a link to the Creative Commons licence, and indicate if changes were made. The images or other third party material in this article are included in the article's Creative Commons licence, unless indicated otherwise in a credit line to the material. If material is not included in the article's Creative Commons licence and your intended use is not permitted by statutory regulation or exceeds the permitted use, you will need to obtain permission directly from the copyright holder. To view a copy of this licence, visit http://creativeco mmons.org/licenses/by/4.0/. The Creative Commons Public Domain Dedication waiver (http://creativecommons.org/publicdomain/ zero/1.0/) applies to the data made available in this article, unless otherwise stated in a credit line to the data. 
survival for ATLL is less than one year, with fewer than four percent of subjects surviving 4 years, despite aggressive chemotherapy [5].

HTLV-1 initially infects T-cells or lymphoid precursors [6] and expresses two viral oncoproteins; Tax, the activator of viral transcription, and helix-basic-zipper protein (HBZ) which is the only viral protein constitutively expressed in all ATLL cells [7]. Tax induces cell proliferation through T-cell receptor (TCR) signaling to nuclear factor $\kappa B(\mathrm{NF} \kappa \mathrm{B})$, confers resistance to apoptosis, and promotes genetic instability, all of which contribute to the initiation of T-cell malignancy [8]. These functions are mediated by the effect of Tax on an array of cellular proteins, described as the "Tax interactome" [9]. However, Tax is also highly immunogenic and cells expressing it at high levels are targeted by cytotoxic $\mathrm{T}$ lymphocytes (CTL) [10]. This results in selection of ATLL cells that suppress Tax and compensate for loss of Tax by acquiring genetic or epigenetic changes in the Tax interactome [7].

In ATLL cells, somatic mutations are frequently found in genes in the TCR signaling pathway [7]. These mutations precede development of detectable disease, can accumulate in predominant clones over many years, are not found in HTLV-1 infected patients who fail to develop ATLL [11] and signal though NFKB to interferon regulatory factor 4 (IRF4) [12]. The IRF4 gene is the most frequently mutated gene in ATLL, with 1 in 4 patients carrying amplification of the IRF4 gene and 1 in 7 individuals acquiring activating nucleotide variants [7]. Highly expressed in ATLL, IRF4 drives cellular proliferation $[13,14]$ and is associated with poor prognosis and therapeutic resistance $[15,16]$. IRF4 and $N F_{K} B$ have been described as master regulators of transcription in ATLL, forming a coherent feed-forward loop that drives cell proliferation and survival [12]. The downstream targets of IRF4 and its mechanism of action in ATLL pathogenesis remains largely uncharacterized. In one study, knockdown of IRF4 resulted in up-regulation of Th1 transcription factors/cytokines including interferon (IFNY) and interleukin 7 receptor (IL7R) [17]. We previously reported that the most common IRF4 mutation in ATLL, K59R, led to increased nuclear localization and transcriptional activity of IRF4, with increased expression of several IRF4-target genes, such as IL2, CCR4, $M Y C N$, and CTLA4 [18].

Based on these findings, we sought to interrogate IRF4 signaling in vivo and determine if IRF4 represents a therapeutic target for ATLL. IRF4 has been identified as a key driver in other lymphoid malignancies, including multiple myeloma [19]. Lenalidomide, and its predecessor, thalidomide, are proprietary immunomodulatory imide drugs (IMiD) compounds of Celgene Corporation, which have potent anti-inflammatory, anti-angiogenic, and immunomodulatory properties [20]. In addition to multiple myeloma, lenalidomide is approved for use in myelodysplastic syndromes and several non-Hodgkin's lymphomas [21-23]. Lenalidomide inhibits proliferation of multiple myeloma and primary effusion lymphoma at least partially by repressing IRF4 expression [24-27]. Pomalidomide treatment reduced IRF4 expression in HTLV-1 infected MT2 cells and increased their susceptibility to NK mediated cytotoxicity [28]. However, TLOM1 cells, an ATLL cell line which does not express Tax, were unaffected by pomalidomide. Here we report the sensitivity of ATLL cells to therapies that directly and indirectly target IRF4 and describe downstream effectors of IRF4 expression in CD4+ T-cells in vivo.

\section{Results}

\section{Proliferation of Tax-negative ATLL cell lines is dependent} on IRF4

Antisense oligonucleotides (ASOs) that directly target IRF4 messenger RNA were used to silence IRF4 gene expression in ATLL cell lines, primary patient-derived ATLL cells, and control cell T-cell lines. The IRF4 ASOs are chimeric gapmer nuclease-resistant oligonucleotides with constrained ethyl chemistry that have high affinity, stability, and tolerability; and are currently in multiple myeloma clinical trials [29]. Cell proliferation in the presence of IRF4 ASO or control ASO was measured over the course of 7 days (Fig. 1a). Proliferation of ATLL cells that express the Tax oncogene was largely resistant to the suppression of IRF4, whereas the proliferation of Tax-negative cells was exquisitely sensitive to IRF4 knockdown in a dose-dependent (Fig. 1b) and time-dependent (Fig. 1c) manner. ASO suppressed IRF4 RNA (Fig. 1d) and protein (Fig. 1e) equally well in Tax-negative and Tax-expressing cells (Fig. 1f) and two different IRF4 ASOs showed similar results (Fig. 1g). Taken together, these data suggest that IRF4 is essential for proliferation of ATLL cells that do not express the viral oncogene Tax.

\section{Proliferation of ATLL cells is suppressed by lenalidomide}

By targeting cereblon, lenalidomide affects the expression of a variety of transcription factors including IRF4 and downstream targets like Myc [27, 30]. Treatment of ATLL cells with lenalidomide resulted in striking suppression of proliferation in a dose dependent manner (Fig. 2a). Within two days of exposure to lenalidomide, ATLL cells were more sensitive than other T-cell lines, as well as OPM2 cells, a multiple myeloma cell line. The proliferation of all ATLL cells tested was suppressed over the course of 8 days (Fig. 2b). Unlike the IRF4 ASO, the effect of lenalidomide was independent of Tax expression. MT2 and MT4 cells, which express Tax, were suppressed along with the Tax-negative ATLL cells (Fig. 2a-d). Like IRF4 


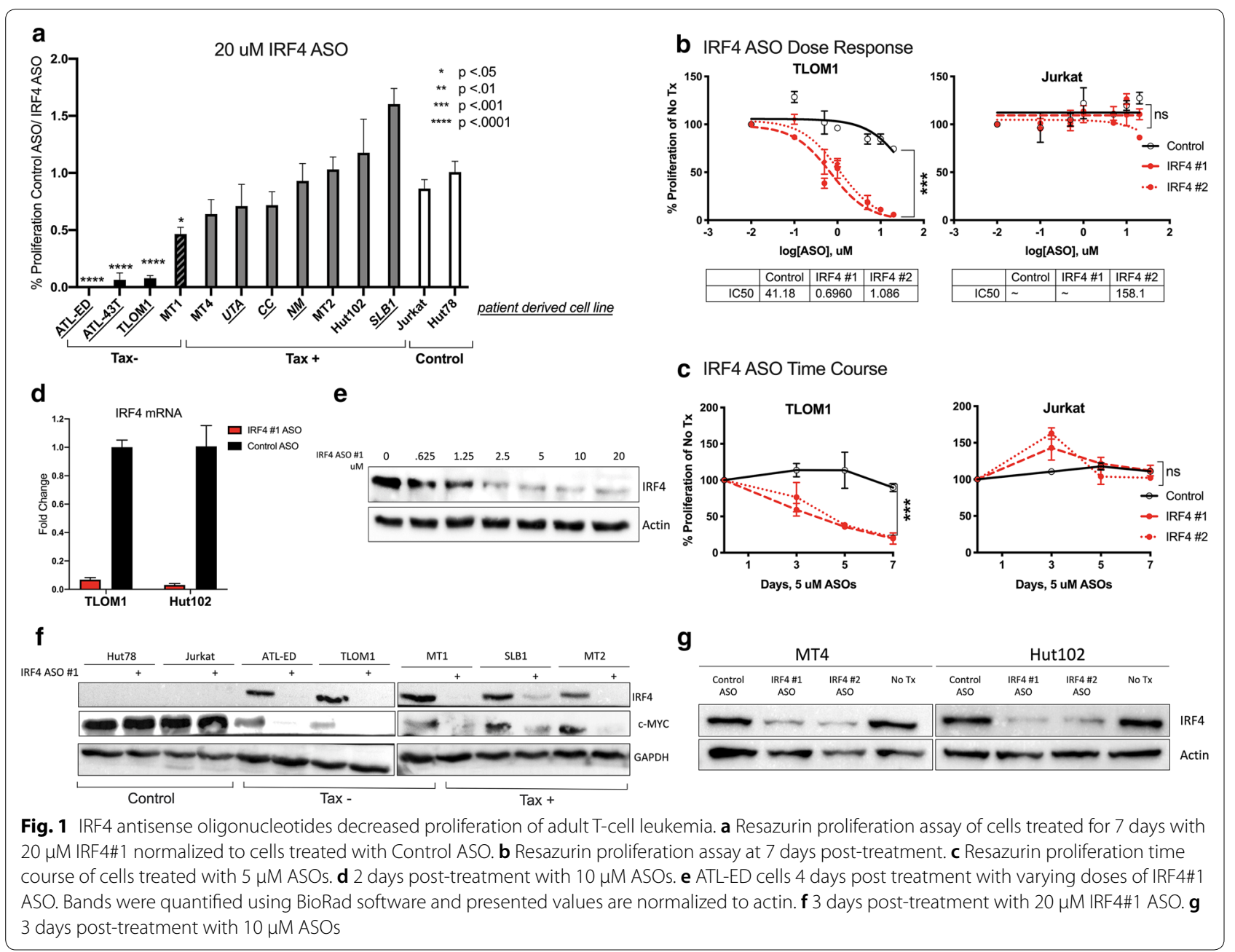

ASO, lenalidomide treatment resulted in decreased IRF4 protein (Fig. 2e). In some cell lines, like MT2, MT4, and ATL43T, the effect of lenalidomide on proliferation was more potent than that of IRF4 ASO. In other cell lines, like TLOM1 and OPM2, the opposite was true (Additional file 1: Figure S1).

To evaluate the efficacy of ASO and lenalidomide in vivo, ATL-ED cells were injected intraperitoneally (ip) into NSG-KIT mice (Fig. 3a). Over the course of 18 days, mice received ip. injections of ASO, lenalidomide, or vehicle (sterile saline). Fewer ATL-ED cells were present in the peripheral blood at the time of sacrifice in the treated animals compared to vehicle control (Fig. 3b-d). These data suggest that lenalidomide is capable of significantly suppressing the proliferation of ATLL cells both in vitro and in vivo.

\section{IRF4 signaling in T-cells}

To understand the mechanisms governing the role of IRF4 in the pathogenesis of ATLL and to discover potential biomarkers for ATLL therapy, we sought to identify downstream targets of IRF4 signaling in CD4+T-cells in vivo. Using GFP-tagged retroviral vectors, murine hematopoietic stem cells (HSC) from CD45.2 mice were transduced with IRF4 (WT), IRF4 (K59R), or empty vector and engrafted into CD45.1 hosts. Overexpression of IRF4 (WT) or IRF4 (K59R) in the bone marrow of host mice led to marked expansion of $\mathrm{T}$ lymphoid cells, but no alteration of B lymphoid or myeloid cell populations (Fig. 4a) [18]. After 4 weeks, RNAseq was performed on GFP + CD 45.2 + CD4 + CD8 - T-cells harvested from the thymus (3 mice for each condition). One hundred and five IRF4 downstream targets were up-regulated in T-cells from both IRF4 (WT) and IRF4 (K59R) mice compared to T-cells harvested from control mice (Additional file 1: Figure S2). The genes associated with IRF4 (WT) 

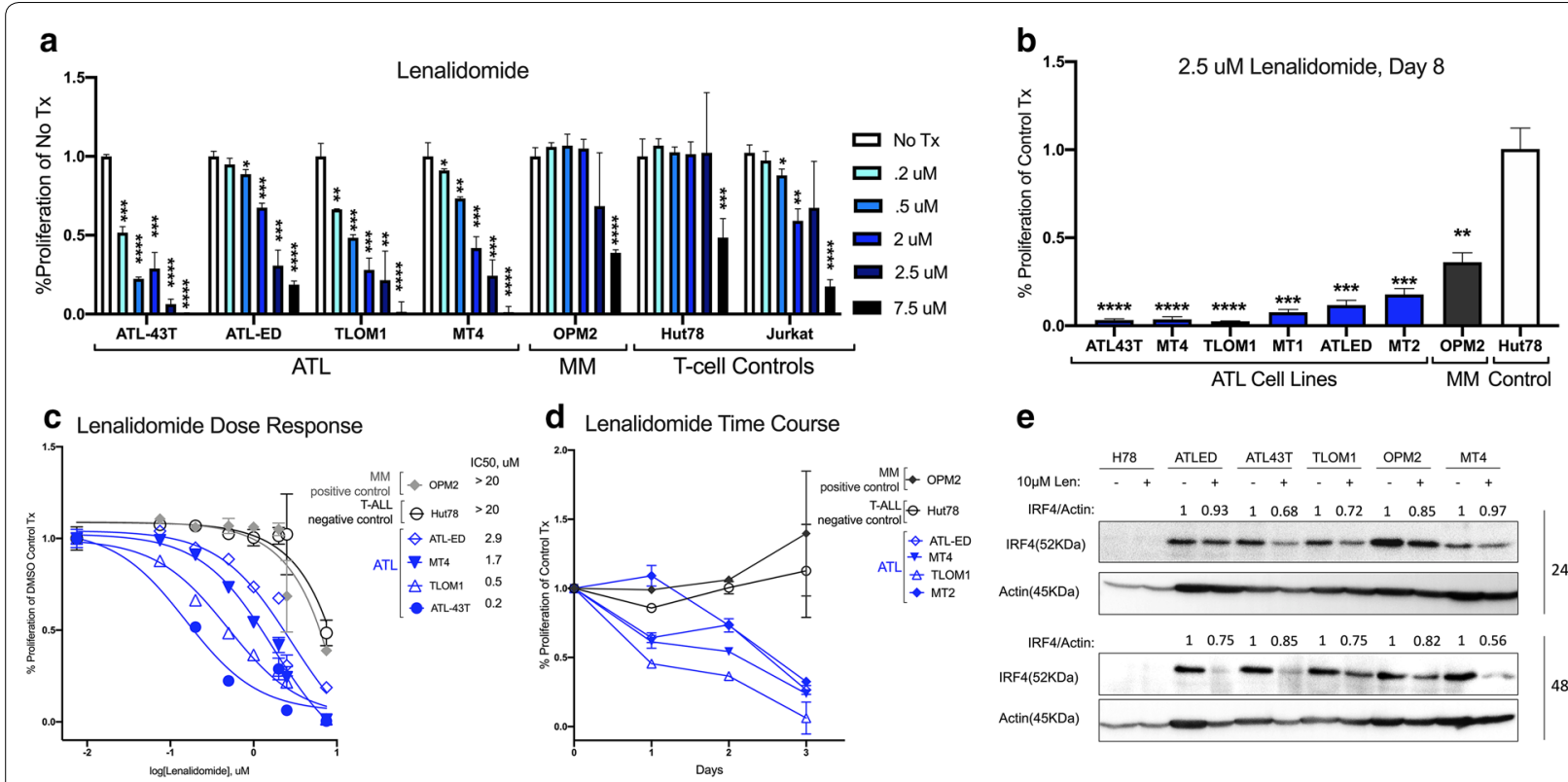

e

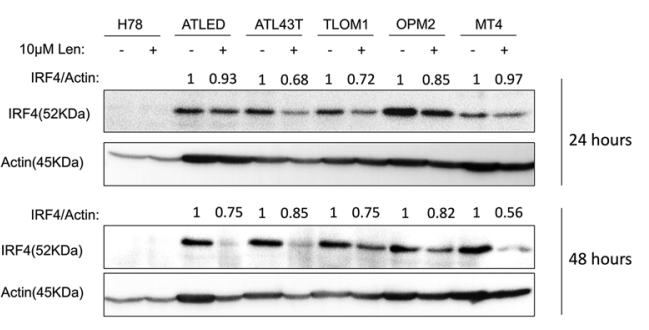

Fig. 2 Lenalidomide decreases proliferation and reduces IRF4 expression in ATLL. a Resazurin proliferation assay of cells treated for 2 days with varying doses of lenalidomide normalized to cells treated with DMSO control. Two-tailed T-tests of each dose compared to DMSO were conducted for each cell line. $\mathbf{b}$ Resazurin proliferation assay at 8 days post-treatment with $2.5 \mu \mathrm{M}$ lenalidomide. Two-tailed T-tests were conducted for each cell line compared to Hut78 control T-cells. c Dose response curves at 4 days post-treatment. IC50s were calculated with Prism Graphpad software. d Proliferation time course of cells treated with $1 \mu \mathrm{M}$ lenalidomide. e Western blot of cells treated for $24 \mathrm{~h}$ with 10 and $20 \mu \mathrm{M}$ lenalidomide. Bands were quantified using BioRad software and presented values are normalized to actin

and IRF4 (K59R) expression included CASP1, CHST2, CLEC12A, CTLA4, FCGR2B, IFI204, IL2RA, IL2RB, KITLG, LAMB2, LY86, MAF, SMAD3, TGFB3, THSD1, TIGIT, TOX2, and TLR2. Many of these genes, such as CTLA4 and TOX2, are also up-regulated in ATLL samples (Additional file 1: Figure S3). In addition to IRF4, transcription factors most closely associated with the genes identified in this study included BATF3 and PRDM1, known IRF4 binding partners (Fig. 4c). These data reveal that overexpression of IRF4 in HSC results in expansion of the $\mathrm{T}$ cell compartment and the expression of factors characteristic of ATLL and capable of promoting lymphoid proliferation downstream of TCR signaling.

\section{Discussion}

Therapeutic nucleic acid-based approaches, including ASOs, offer the potential to yield drugs, based on gene sequence information alone, for targets that have proven to be intractable to alternative drug modalities, such as transcription factors like IRF4 [31]. Therapeutic ASOs have common chemical and biological properties and are generally safe and well-tolerated in the clinic. This has led to several recent new drug approvals including Tegsedi ${ }^{\mathrm{TM}}$, Waylivra $^{\mathrm{TM}}$ and the blockbuster drug Sprinraza ${ }^{\mathrm{TM}}$ for the treatment of patients with the devastating neurodegenerative disease spinal muscular atrophy [32]. Continued efforts to improve upon the stability and potency of ASOs has resulted in the discovery of a next-generation class of ASOs that employ $2^{\prime}-4^{\prime}$ constrained ethyl (cEt) residues and exhibit significantly enhanced in vitro and in vivo potency compared to earlier generation ASO molecules [33]. More recently, these next-generation cEt-containing ASOs targeted to previously undruggable tumor cell targets have shown therapeutic promise for the treatment of cancer. The first cEt-containing ASOs to be evaluated clinically are AZD9150/Danvatirsen, which targets the transcription factor STAT3, and ION-560131/ $\mathrm{AR}_{\mathrm{RX}}$, that targets all forms of the androgen receptor [33, 34]. Both of these novel therapeutics have demonstrated good tolerability and efficacy in clinical trials. Danvatirsen has shown strong single-agent antitumor activity in several cancer patient populations in early clinical studies. Moreover, ION-560131/AR $\mathrm{RX}_{\mathrm{RX}}$ has shown encouraging monotherapy clinical efficacy in late-stage metastatic prostate cancer patients.

There are no effective therapies for ATLL, the median survival time for this malignancy is measured in months, and in the U.S., minorities are disproportionately affected. Therapeutic options that effectively target ATLL cells are urgently needed. Recent breakthroughs in our understanding of the genomics of ATLL have revealed that this malignancy selects for constitutively active TCR 


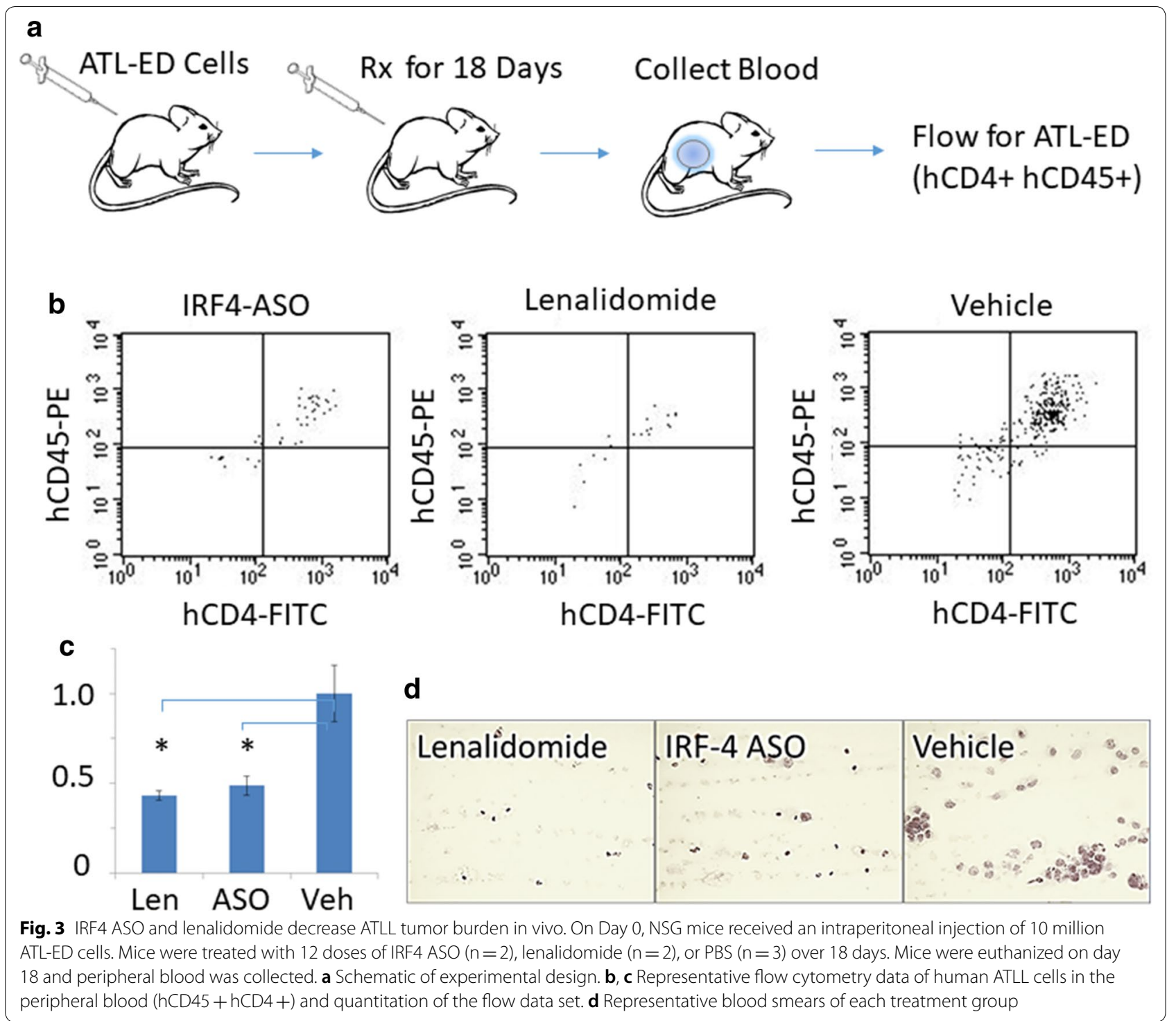

signaling. The TCR signaling pathway is initially activated by the Tax oncogene in early stages of HTLV-1 infection, which drives transformation and immortalization. In HTLV-1 transformed T-cells, the TCR provides a signal driving transcription through master regulators IRF4 and $\mathrm{NF}_{\kappa} \mathrm{B}$ in a feed-forward loop. Later, somatic activating mutations in the TCR pathway genes themselves replace the need for Tax, promoting immune evasion and disease progression. Lenalidomide, an FDA approved drug currently used to treat multiple myeloma and other lymphoid malignancies, indirectly suppresses IRF4. As a prerequisite for a clinical trial, these studies were performed to determine if lenalidomide treatment affects the proliferation of ATLL cells in tissue culture and animal models, and to identify the downstream targets of IRF4 in CD4+ T-cells in vivo.

First, the ATLL cells tested were sensitive to lenalidomide. Both dose-dependent and time- dependent inhibition of ATLL cells was more pronounced than that of other sensitive control cell lines, including one derived from multiple myeloma. Lenalidomide was efficacious against ATLL both in cell culture and in mouse xenograft experiments. The mechanism underlying the effect of lenalidomide on ATLL cells is not clear. While lenalidomide suppresses IRF4 expression and ATLL cell proliferation, targeted knockdown of IRF4 using ASO only suppressed proliferation of the Tax-negative subset of ATLL cells. This suggests that IRF4 is essential for the proliferation of Tax-negative ATLL cells and also suggests 


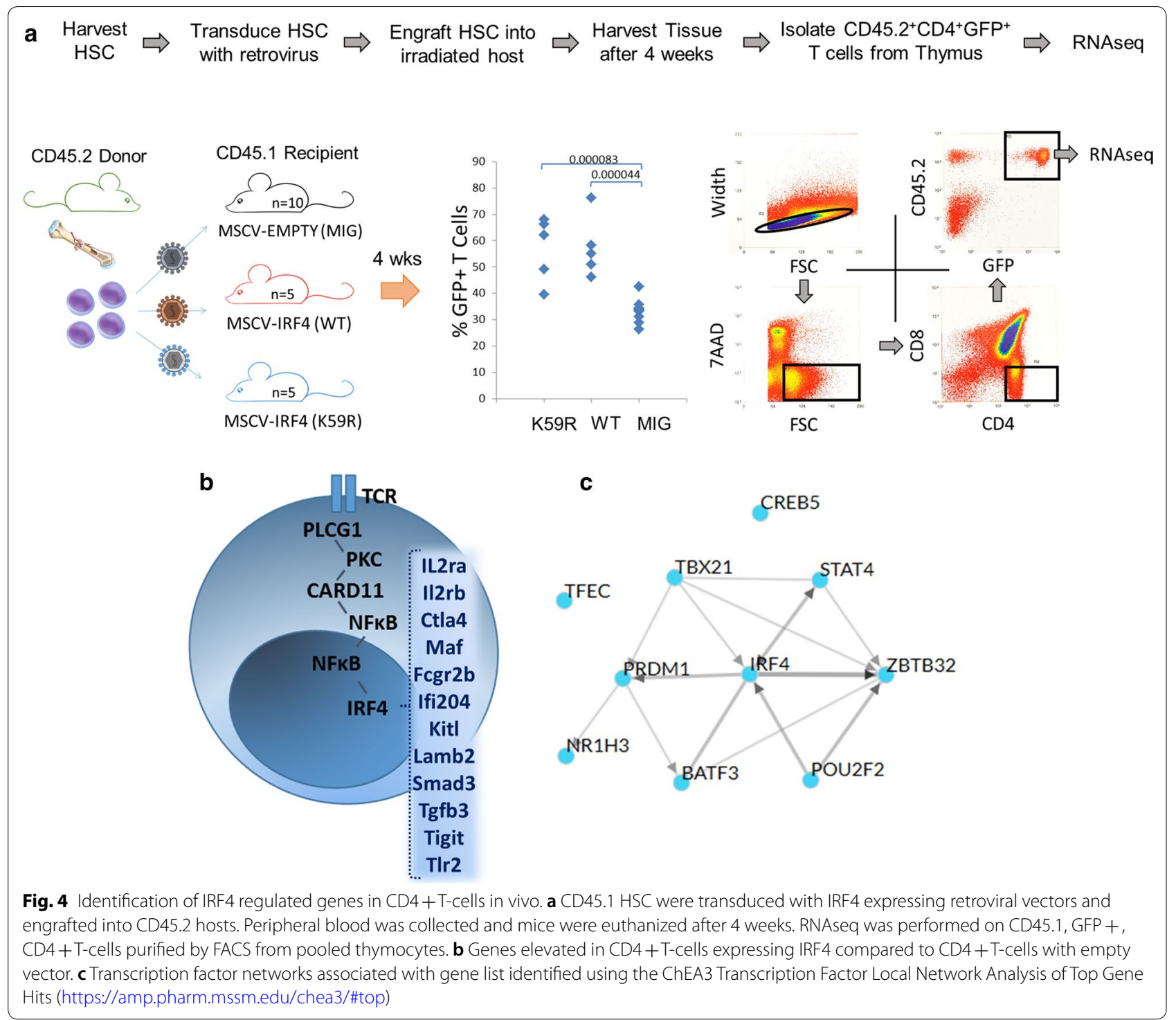

that lenalidomide suppression of ATLL cells is mediated by more than one mechanism, as has been described in multiple myeloma.

Second, the IRF4 ASO results indicate that ATLL cell lines that retain expression of the viral oncogene Tax are able to proliferate in the absence of IRF4, whereas IRF4 is essential for proliferation of ATLL cells that no longer express Tax. It is unclear if IRF4 dependency in Tax-negative ATLL cells is associated with acquisition of specific mutations or whether it can be bypassed by overexpression of the Tax oncogene. This discovery exposes a previously unknown relationship between Tax and IRF4. Since Tax expression is a strong selective disadvantage during lymphomagenesis and is typically silenced, ATLL cells in the context of tumor immunity may be more sensitive to IRF4-targeted therapies than the same cells cultured ex vivo or as xenografts in immunodeficient mouse models. A pilot study of lenalidomide in a small cohort of Japanese patients with ATLL showed significant clinical response [35].

Third, while constitutive TCR signaling through NFкB to IRF4 regulates ATLL, the downstream targets of IRF4 that drive ATLL cell proliferation are not known. Identifying these downstream effectors will not only provide mechanistic insights into ATLL pathogenesis but will also provide biomarkers for disease progression and additional therapeutic targets. Overexpression of IRF4 in HSC in the bone marrow of mice promoted the expansion of T-cells in the peripheral blood within 4 weeks. Examination of the transcriptome of these expanded 
CD4 + T-cells in the thymus revealed a subset of genes likely to be involved in T-cell proliferation and ATLL progression. Half of the genes identified were previously identified by Krishnamoorthy et al. as factors regulated by IRF4 downstream of TCR signaling in T-cells in a transgenic model [36]. Notably, several of the genes encode ATLL cell surface markers (IL2RA also known as CD25), checkpoint regulators (CTLA4, TIGIT), and key regulators of T-cell proliferation (MAF, KITLG, TGFB3). Several other of the IRF4 regulated factors we identified have been implicated in ATLL pathogenesis. TNSF11 encodes RANKL which mediates hypercalcemia characteristic of ATLL [37]. JAG1 is a Notch ligand, and Notch signaling is activated in ATLL [38]. Our previous studies showed that ETS1 is a target of Tax transactivation [39] and that BLK is overexpressed in ATLL [40]. A previous study examined IRF4-induced gene expression in TCR-driven CD8 + T-cells from wild type and knockout animals, and identified key regulators: PRDM1 (which encodes Blimp-1), eomesodermin (EOMES), runt-related transcription factor 3 (Runx3), TCF7, and IL7R [41]. These genes may represent new therapeutic targets for ATLL and may be useful as biomarkers in a clinical trial of Lenalidomide.

\section{Conclusions}

Our recent experience testing the efficacy of checkpoint inhibitors in ATLL highlights the powerful role of immunity in ATLL pathogenesis and progression, and the desperate need for targeted therapies [6]. Elucidating the mechanism by which TCR signaling through IRF4 is driving ATLL is an essential step in identifying and targeting these critical factors. The IRF4 ASO has advanced into a clinical trial in multiple myeloma (NCT04398485). Lenalidomide has advanced in a clinical trial with combination chemotherapy in ATLL (NCT04301076).

\section{Methods}

\section{Cell culture}

TLOM1, MT1, and ED40515 Tax-negative ATL cell lines were obtained from Edward Harhaj (Penn State University) and OPM2 cells were kindly provided by Kareen Azab (Washington University). The Hut102, ATL-ED, ATL-43T, and SLB1 cell lines were gifts from Patrick Green (Ohio State University). Jurkat, 293T, MT2, and MT4 cells were obtained from the National Institutes of Health AIDS Repository. Cell lines were maintained at $37{ }^{\circ} \mathrm{C}$ and $5 \% \mathrm{CO}_{2}$ in complete medium supplemented with $10 \%$ fetal bovine serum, $4 \mathrm{mM}$ L-glutamine, 100 units $/ \mathrm{ml}$ penicillin, and $100 \mu \mathrm{g} / \mathrm{ml}$ streptomycin. PBMCs and T-cell lines, including Jurkat, MT2, MT4, TLOM1,
MT1, and ED40515 cells, were maintained in complete RPMI medium.

\section{Therapeutics}

ASOs were from Ionis Pharmaceutical. Lenalidomide was purchased from AdooQ Bioscience (A10522-10 mM-D) presolubilized in DMSO. Lenalidomide was stored at room temperature, never frozen, and discarded after 2 weeks.

\section{Western Blotting}

Cells were lysed in Tris-HCl, pH 6.8, with $2 \%$ Igepal CA630, 2\% SDS, $10 \mathrm{mM}$ sodium glycerophosphate, $10 \mathrm{mM}$ sodium fluoride, $2.5 \mathrm{mM}$ sodium pyrophosphate, $1 \mathrm{mM}$ sodium orthovanadate, and EDTA-free protease inhibitor mixture (Roche Applied Science/Sigma). Lysates were sonicated on ice for 3 cycles of $30 \mathrm{~s}$ on $30 \mathrm{~s}$ off. Protein concentration was determined using the bicinchoninic acid assay. Equal amounts of protein (40 ug) were mixed with $4 \times$ Sample buffer $(25 \%$ Tris-HCL $\mathrm{pH}$ 6.8, 13\% water, $0.8 \%$ SDS, $40 \%$ Glycerol, bromophenol blue, 20\% 2-Mercapto ethanol) and briefly boiled before loading on to $10 \%$ SDS-PAGE gel. Buffers for gel, transfer, and washing steps followed protocols described by Proteintech. Blots were blocked for $1 \mathrm{~h}$ in $5 \%$ proteasefree BSA at room temperature. Antibodies were diluted in $5 \%$ protease-free BSA. Blots were imaged by enhanced chemiluminescence using a Chemidoc imager (Bio-Rad) and HRP substrate Clarity ${ }^{\mathrm{TM}}$ Western ECL Substrate (1705060) (Bio-rad). The following antibodies were used for Western blots: mouse primary monoclonal antibody to IRF4 (sc-48338) and to c-MYC (sc-40), rabbit primary monoclonal antibody to $\beta$-Actin (cell signaling 13E5), and anti-rabbit monoclonal antibody (cell signaling 4970).

\section{Proliferation assay}

Cells were plated at 10,000 cells per well in $200 \mu \mathrm{L}$ in a round bottom 96 well plate. Plates were covered and incubated at $37^{\circ} \mathrm{C}$. At the specified time points, $20 \mu \mathrm{L}$ of AlamarBlue (ThermoFisher Scientific) was added to the wells to achieve a final concentration of $0.15 \mathrm{mg} / \mathrm{ml}$. Plates were placed back in the incubator and absorbance was read after $2 \mathrm{~h}$ on the SpectraFluor Plus Spectrophotometer (Tecan).

\section{Quantitative PCR}

RNA was extracted using TRIzol reagent. Total RNA was used as template for reverse transcription and amplification of cDNAs in a three-step amplification protocol using the iTaq Universal SYBR Green one-step kit (Bio$\mathrm{Rad}$ ) on a Bio-Rad CFX Connect real-time system with 
an extension temperature of $65{ }^{\circ} \mathrm{C}$. Exon-exon junctionspanning primers were designed to reduce background from genomic DNA. The following primers were used for qRT-PCR: HGPRT1 (forward), GCCCTGGCGTCGTGA TTAGT; HGPRT1 (reverse), GTTGACTGGTCATTA CAATA; IRF4 (forward), TTGGCGTTCTCAGACTGC CG; IRF4 (reverse), AACGCTTGCAGCTCTGACAA. Cycle number (Ct value) for each measured transcript was converted to ratios of transcript abundance by taking the antilog to the base 2 of $(-1 \times \mathrm{Ct})$ value for each transcript and dividing that by the antilog to the base 2 of $(-1 \times \mathrm{Ct})$ value for hypoxanthine guanine phosphoribosyl transferase based on the assumption of a $100 \%$ amplification efficiency.

\section{In vivo studies}

All animal studies were performed in accordance with human research protocols approved by the division of comparative medicine and the Institutional Animal Care and Use Committee (IACUC; Animal Welfare Assurance \#A-3381-01) at Washington University in Saint Louis. 4 month old NSG mice were injected intraperitoneally with $10^{6}$ ATL-ED in $150 \mu \mathrm{L}$ of PBS. Mice were treated with intraperitoneal injections with two days on one day off for 12 doses over 18 days. IRF4 ASO treatment included $50 \mathrm{mg} / \mathrm{kg}$ suspended in $200 \mu \mathrm{L}$ saline based on recommendations from the manufacturer (Ionis pharmaceuticals). Lenalidomide treatment included $50 \mathrm{mg} /$ $\mathrm{kg}$ suspended in $200 \mu \mathrm{L}$ saline. Control mice were treated with $200 \mu \mathrm{L}$ PBS. ASOs and lenalidomide were initially solubilized in DMSO and diluted to a final dosed concentration of less than 10\% DMSO. Mice were sacrificed at day 18 post tumor injection and blood smears and flow cytometry were used to assess peripheral blood leukemia burden.

\section{Transduction of murine hematopoietic stem cells and transplantation into recipient mice}

$150 \mathrm{mg} / \mathrm{kg} 5$-fluorouracil was administered to Donor C57/B6 CD45.1 mice 6 days before bone marrow harvest. Harvested marrow was enriched for $\mathrm{Sca}-1^{+}$cells by autoMACS (Miltenyi). Sca-1+enriched cells were adjusted to $5 \times 10^{5}$ cells $/ \mathrm{ml}$ in stem cell media cocktail containing Stempro34 serum-free medium supplement (Gibco), $10 \mathrm{ng} / \mathrm{ml}$ stem cell factor (R\&D Systems), $100 \mathrm{ng} / \mathrm{ml}$ mouse thrombopoietin, 100 units/ml penicillin, $100 \mu \mathrm{g} / \mathrm{ml}$ streptomycin, $4 \mu \mathrm{g} / \mathrm{ml}$ Polybrene, and $2 \mathrm{~mm}$ glutamine. MSCV particles were generated in $293 \mathrm{~T}$ cells by calcium phosphate-mediated co-transfection of pCL-ECO packaging plasmid with either the empty MSCV-IRES-GFP retroviral vector or vector with coding sequence for WT IRF4 or K59R mutant
IRF4 inserted by LR clonase recombinational cloning and harvested from the medium by ultracentrifugation. Sca- $1^{+}$enriched donor marrow cells were transduced with MSCV retroviral particles by spin-inoculation at $250 \times g$ at room temperature for $2 \mathrm{~h}$, followed by incubation for $1 \mathrm{~h}$ at $37^{\circ} \mathrm{C}$, and then transplanted by retroorbital injection into lethally irradiated (9.5 grays) C57/B6 CD45.2 recipients $(n=10$ for empty vector and 5 each for WT IRF4 and K59R mutant IRF4). Four weeks after engraftment, peripheral blood was collected, and FACS was used to determine the abundance of $\mathrm{CD} 45.1^{+}, \mathrm{GFP}^{+}$myeloid cells $(\mathrm{Gr}-1+, \mathrm{Mac}-1+)$, B cells $\left(\mathrm{B} 220^{+}\right)$, and T-cells $\left(\mathrm{CD} 4^{+}, \mathrm{CD} 8^{+}\right)$. Mouse strains used for this study were obtained from the Jackson Laboratory (Bar Harbor, ME).

\section{RNA sequencing}

Total RNA was obtained from flow sorted GFP + CD45.2 + CD4 + CD8- T-cells harvested from the thymus of three mice in each group (empty vector / MIG; wild-type IRF4/ WT; and mutant IRF4 / K59R) using RNeasy (QIAGEN). RNA was submitted to the Genome Technology Access Center at Washington University for RNA sequencing (RNAseq) analysis, processed for low quantity input with Takara-Clontech SMARTer, and sequenced on a NovaSeq S4, $2 \times 150$ platform. Reads were aligned to the reference genome using STAR, and gene counts were derived from uniquely aligned reads using Subread:featureCount. BAM files for RNAseq and probe capture DNA were submitted to the Sequence Read Archive Database under BioProject accession number PRJNA658553.

\section{Statistics}

Data were analyzed by two-tailed unpaired Student's $t$ test for samples of equal variance for statistical significance. Error bars specify standard error. Statistics were conducted using Prism GraphPad 8.0.

\section{Supplementary information}

Supplementary information accompanies this paper at https://doi. org/10.1186/s12977-020-00535-z.

Additional file 1: Figure S1. Sensitivity of cell lines to combination of lenalidomide and IRF4 ASO. Cells were treated for 2 days with either 10 uM IRF4 ASO, 2.5 uM lenalidomide, Combination, or Control ASO + DMSO Treatment. Resazurin proliferation assay were conducted and values are presented as normalized to control treatment for each cell line. Figure S2. IRF4 gene targets up-regulated in primary T-cells. Total RNA was obtained from flow sorted GFP+ CD45.2+ CD4+ CD8-T-cells harvested from the thymus of three mice in each group and submitted to the Genome Technology Access Center at Washington University for RNA sequencing (RNAseq) analysis. Normalized gene counts for each 
of the 9 samples were divided by the average number of normalized counts for the 3 MIG samples. Colors indicate fold increase for each gene in each sample over average control (MIG) value for each gene. Genes listed are those that were expressed ( $>10$ reads) and elevated ( $>2$ fold) in cells expressing WT IRF4 and IRF4 K59R. Figure S3. IRF4 gene targets confirmed in primary ATL. Data from an ATLL gene expression microarray study was downloaded from the Gene Expression Omnibus at the NCBI (GEO accession: GSE33615). In the original study, RNA was extracted from PBMCs isolated from patients with acute $(n=26)$, chronic $(n=20)$, lymphomatous $(n=1)$, and smoldering $(n=4)$ ATLL, and compared to RNA obtained from CD4+ cells from 21 normal subjects. In this study, values for CTLA4 and TOX2 were normalized to actin (ACTB) then represented as fold-Patient 10 (a smoldering ATLL sample with the lowest proviral load in the study). A) Correlation of TOX2 and CTLA4 to IRF4 expression in ATLL. B) Expression of TOX2, CTLA4, and IRF4 in IRF4 HI ATLL samples compared to normal T-cells. C) Expression of TOX2, CTLA4, and IRF4 in acute, chronic, lymphoma, and smoldering subtypes of ATLL.

\section{Acknowledgements}

We thank Andrew Martens, JC Ramos, the McDonnell Genome Institute, and the Siteman Cancer Center Flow Cytometry and Genomic Technology Access Center in the Department of Genetics at Washington University School of Medicine for their assistance. These core laboratories are partially supported the NCI Cancer Center Support Grant P30 CA91854 to the Siteman Cancer Center and by ICTS/CTSA Grant UL1TR002345 from the National Center for Research Resources (NCRR), a component of the National Institutes of Health $(\mathrm{NIH})$, and NIH Roadmap for Medical Research. This publication is solely the responsibility of the authors and does not necessarily represent the official view of NCRR or NIH.

\section{Authors' contributions}

DAR, SLO, JCH, HS conducted experiments, YK, TZ, and ARM provided materials, DAR, GC, and LR performed data analysis, DAR wrote the initial draft. All authors read and approved the final manuscript.

\section{Funding}

This study was funded by grants P01 CA100730, R01 CA063417, R21 CA234640, R21 Al26652, and funds from the Siteman Cancer Center.

\section{Availability of data and materials}

Transcriptomic data were submitted to Sequence Read Archive Database. All other data sets are available upon request from the corresponding author.

\section{Ethics approval and consent to participate}

Animal experiments were carried out in a humane fashion and approved by the Institutional Animal Care and Use Committee (IACUC; Animal Welfare Assurance \# A-3381-01).

\section{Consent for publication}

Not applicable.

\section{Competing interests}

Drs Kim, Zhou, and MacLeod are employed by lonis Pharmaceuticals who have manufactured the IRF4 ASOs and have ongoing clinical trials with these reagents. Other authors have no funding, honoraria, and stock interests to disclose.

\section{Author details}

${ }^{1}$ Division of Oncology, Department of Medicine, Washington University in St. Louis, 660 S Euclid Ave, Box 8069, St Louis, MO 63110, USA. ${ }^{2}$ Ionis Pharmaceuticals, Carlsbad, CA, USA.

Received: 3 July 2020 Accepted: 17 August 2020

Published online: 28 August 2020

\section{References}

1. Gessain A, Cassar O. Epidemiological aspects and world distribution of HTLV-1 infection. Front Microbiol. 2012;3:388.

2. Chang YB, Kaidarova Z, Hindes D, Bravo M, Kiely N, Kamel H, Dubay D, Hoose B, Murphy EL. Seroprevalence and demographic determinants of human T-lymphotropic virus type 1 and 2 infections among first-time blood donors - United States, 2000-2009. J Infect Dis. 2014;209:523-31.

3. Ureshino H, Shindo T, Nishikawa H, Watanabe N, Watanabe E, Satoh N, Kitaura K, Kitamura H, Doi K, Nagase K, et al. Effector regulatory T-cells reflect the equilibrium between antitumor immunity and autoimmunity in adult T-cell leukemia. Cancer Immunol Res. 2016;4:644-9.

4. Shimoyama M. Diagnostic criteria and classification of clinical subtypes of adult T-cell leukemia-lymphoma: a report from the Lymphoma Study Group. Br J Hematol. 1991;79:428-37.

5. Katsuya H, Ishitsuka K, Utsunomiya A, Hanada S, Eto T, Moriuchi Y, Saburi Y, Miyahara M, Sueoka E, Ike N, et al. Treatment and survival among 1594 patients with ATL. Blood. 2015;126:2570-7.

6. Rauch DA, Conlon KC, Janakiram M, Brammer JE, Harding JC, Ye BH, Zang XX, Ren X, Olson S, Cheng X, et al. Rapid progression of adult T-cell leukemia/lymphhoma as tumor infiltrating Treg cells after PD-1 blockade. Blood. 2019;134:1406-14.

7. Kataoka K, Nagata Y, Kitanaka A, Shiraishi Y, Shimamura T, Yasunaga J, Totoki Y, Chiba K, Sato-Otsubo A, Nagae G, et al. Integrated molecular analysis of adult T-cell leukemia/lymphoma. Nat Genet. 2015;47:1304-15.

8. Currer R, VanDuyne R, Jaworski E, Guendel I, Sampey G, Das R, Narayanan A, Kashanchi F. HTLV Tax: a fascinating multifunctional co-regulator of viral and cellular pathways. Front Microbiol. 2012;3:406.

9. Boxus M, Twizere J-C, Legros S, Dewulf J-F, Kettmann R, Willems L. The HTLV-I Tax interactome. Retrovirology. 2008;5:76.

10. Kannagi M, Hasegawa A, Nagano Y, lino T, Okamura J, Suehiro Y. Maintenance of long remission in adult T-cell leukemia by Tax-targeted vaccine: a hope for disease-preventive therapy. Cancer Sci. 2019;110:849-57.

11. Rowan A, Dillon R, Witkover A, Melamed A, Demontis M-A, Gillet N, Mun LJ, Bangham C, Cook L, Fields P, Taylor G. Evolution of retrovirus-infected premalignant T-cell clones prior to adult T-cell leukemia/lymphoma diagnosis. Blood. 2020;135:2023-32.

12. Wong RWJ, Tan TK, Amanda S, Ngoc PCT, Leong WZ, Tan SH, Asamitsu K, Hibi Y, Ueda R, Okamoto T, et al. Feed-forward regulatory loop driven by IRF4 and NF-kB in adult T-cell luekmeia/lymphoma. Blood. 2020;135:934-47.

13. Imaizumi Y, Kohno T, Yamada Y, Ikeda S, Tanaka Y, Tomonaga M, Matsuyama T. Possible involvement of interferon regulatory factor 4 (IRF4) in a clinical subtype of adult T-cell leukemia. Jpn J Cancer Res. 2001;92:1284-92.

14. Sawada L, Nagano Y, Hasegawa A, Kanai H, Nogami K, Ito S, Sato T, Yamano Y, Tanaka Y, Masuda T, Kannagi M. IL-10-mediated signals act as a switch for lymphoproliferation in human T-cell leukmeia virus type-1 infection by activating the STAT3 and IRF4 pathways. PLOS Pathog. 2017;13:e1006597.

15. Ramos JC, Ruiz P, Ratner L, Reis IM, Brites C, Pedroso C, Byrne GE, Toomey $\mathrm{NL}$, Andela V, Harhaj EW, et al. IRF-4 and c-Rel expression in antiviralresistant adult T-cell leukemia/lymphoma. Blood. 2007;109:3060-8.

16. Nakagawa M, Shaffer AL, Ceribelli M, Zhang M, Wright G, Huang DW, Xiao W, Powell J, Petgrus MN, Yang Y, et al. Targeting the HTLV-1-regulated BATF3/IRF4 transcriptional network in adult T-cell leukemia/lymphoma. Cancer Cell. 2018;34:286-97.

17. Refaat A, Zhou Y, Suzuki S, Takasaki I, Koizumi K, Yamaoka S, Tabuchi Y, Saiki I, Sakurai H. Distinct roles of transforming growth factor-betaactivated kinase 1 (TAK1)-c-Rel and interferon regulatory factor 4 (IRF4) pathways in human T cell lymphotropic virus 1-transformed T helper 17 cells producing interleukin-9. J Biol Chem. 2011;2866:21092-9.

18. Cherian MA, Olson S, Sundaramoorthi H, Cates K, Cheng X, Harding J, Martens A, Challen GA, Tyagi M, Ratner L, Rauch D. An activating mutation of IRF4 unique to adult T-cell leukemia. J Biol Chem. 2018;293:6844-58.

19. Shaffer AL, Embre NC, Lamy L, Ngo VN, Wright G, Xiao W, Powell J, Dave S, Yu X, Zhao H, et al. IRF4 addiction in multiple myeloma. Nature. 2008:454:226-31.

20. Kritharis A, Coyle M, Sharma J, Evens AM. Lenalidomide in non-Hodgkin lymphoma: biological perspectives and therapeutic opportunities. Blood. 2015;125:2471-6. 
21. Arora M, Gowda S, Tuscano J. A comprehensive review of lenalidomide in B-cell non-Hodgkin lymphoma. Ther Adv Hematol. 2016;7:209-21.

22. Holstein SA, Suman VJ, McCarthy PL. Update on the role of lenalidomide in patients with multiple myeloma. Ther Adv Hematol. 2018;9:175-90.

23. Talati C, Sallman D, List A. Lenalidomide: myelodysplastic syndromes with del(51) and beyond. Semin Hematol. 2017;54:159-66.

24. Zhu YX, Kortuem KM, Stewart AK. Molecular mechaism of action of immune-modulatory drugs thalidomide, lenalidomide and pomalidomide in multple myeloma. Leukemia Lymphoma. 2013:54:683-7.

25. Jourdan E, Leblond V, Maisonneuve H, Benhadji KA, Hossain AM, Nguyen TS, Woolridge JE, Moreau PA. A multicenter phase II study of singleagent enzastaurin in previously treated multiple myeloma. Leukemia Lymphoma. 2014;55:2013-7.

26. Kronke J, Udeshi ND, Narta A, Grauman P, Hurst SN, McConkey M, Svinkina T, Heckl D, Corner E, Li X, et al. Lenalidomide causes selective degradation of IKZF1 and IKZF3 in multiple myeloma cells. Science. 2014;343:301-5.

27. Lu G, Middleton RE, Sun H, Naniong M, Ott CJ, Mitsiades CS, Wong KK, Bradner JE, Kaelin WG. The myeloma drug lenalidomide promotes the cereblon-dependent destruction of Ikaros proteins. Science. 2014:343:305-9.

28. Davis DA, Shrestha P, Aisabor Al, Stream A, Galli V, Pise-Masison CA, Tagawa T, Ziegelbauer JM, Franchini G, Yarchoan R. Pomalidomide increases immune surface marker expression and immune recognition of oncovirus-infected cells. Oncoimmunology. 2018;8:e1546544.

29. Zhou T, Kim Y, MacLeod AR. Targeting long noncoding RNA with antisense oligonucleotide technology as cancer therapeutics. In: Zhang YF, et al., editors. Methods in molecular biology, volume 1402. New York: Spring; 2016. p. 199-213.

30. Bjorklund CC, Lu L, Kang J, Hagner PR, Havens CG, Amatenangelo M Wang M, Ren Y, Cuoto S, Breider M, et al. Rate of CRL4 (CRBN) substrate Ikaros and Aiolos degradation underlies differential activity of lenalidomide and pomalidomide in multiple myeloma cells by regulation of c-Myc and IRF4. Blood Cancer J. 2015;5:e354.

31. Bennett CF. Therapeutic antisense oligonucleotides are coming of age. Annu Rev Med. 2019;70:307-21.

32. Finkel RS, Mercuri E, Darras BT, Connolly AM, Kuntz NL, Kirschner J, Chiriboga CA, Saito K, Servais L, Tizzano E, et al. Nusinersen versus sham control in infantile-onset spinal muscular atropy. ENDEAR Study Group. N Engl J Med. 2017;377:1723-32.

33. Hong D, Kurzrock R, Kim Y, Woessner R, Younes A, Nemunaitis J, Fowler N, Zhou T, Schmidt J, Jo M, et al. AZD9150, a next-generation antisense-oligonucleotide inhibitor of STAT3 with early evidence of clinical activity in lymphoma and lung cancer. Sci Transl Med. 2015:18:314ra185

34. Reilley MJ, McCoon P, Cook C, Lyne P, Kurzrock R, Kim Y, Woessner R, Younes A, Nemunaitis J, Fowler N, et al. STAT3 antisense oligonucloeotide AZD9150 in a subset of patients with heavily pretreated lymphoma results of a phase 1b trial. J Immunother Cancer. 2018;16:119.

35. Ishida T, Fujiwara H, Nosaka K, Taira N, Abe Y, Imaizumi Y, Moriuchi Y, Jo T, Ishizawa K, Tobinai K, et al. Multicenter phase II study of lenalidomide in relapsed or recurrent adult T-cell leukemia/lymphoma: ATLL-002. J Clin Oncol. 2016;34:4086-93.

36. Krishnamoorthy V, Kannaganat S, Maienschein-Cline M, Cook SL, Chen J, Bahroos N, Sievert E, Corse E, Chong A, Sciammas R. The IRF4 gene regulatory module functions as a read-write integrator to dynamically coordinate Thelper cell fate. Immunity. 2017;47:481-97.

37. Nosaka K, Miyamoto T, Sakai T, Mitsuya H, Suda T, Matsuoka M. Mechanism of hypercalcemia in adult T-cell leukemia: overexpression of receptor activator of nuclear factor kappaB ligand on adult T-cell leukemia cells. Blood. 2002;99:634-40.

38. Pancewicz J, Taylor JM, Datta A, Baydoun HH, Waldmann TA, Hermine O, Nicot C. Notch signaling contributes to proliferation and tumor formation of human T-cell leukemia virus type 1-associated adult T-cell leukemia. Proc Natl Acad Sci USA. 2010;107:16619-24.

39. Trejo SR, Fahl WE, Ratner L. The tax protein of human T-cell leukemia virus type 1 mediates the transactivation of the c-sis/platelet-derived growth factor-B promoter through interactions with zinc finger transcription factors Sp1 and NGFI-A/Egr-1. J Biol Chem. 1997;272:27411-21.

40. Ratner L, Rauch D, Abel H, Caruso B, Noy A, Barta SK, Parekh S, Ramos JC, Ambinder R, Phillips A, et al. Dose-adjusted EPOCH chemotherapy with bortezomib and raltegravir for human T-cell leukemia virus-associated adult T-cell leukemia lymphoma. Blood Cancer J. 2016;6:3408.

41. Man K, Miasari M, Shi W, Xin A, Henstridge DC, Preston S, Pellegrini M, Belz GT, Smyth GK, Febbraio MA, et al. The transcription factor IRF4 is essential for TCR affinity-mediated metabolic programming and clonal expansion of T-cells. Nat Immunol. 2014;14:1155-65.

\section{Publisher's Note}

Springer Nature remains neutral with regard to jurisdictional claims in published maps and institutional affiliations.
Ready to submit your research? Choose BMC and benefit from:

- fast, convenient online submission

- thorough peer review by experienced researchers in your field

- rapid publication on acceptance

- support for research data, including large and complex data types

- gold Open Access which fosters wider collaboration and increased citations

- maximum visibility for your research: over $100 \mathrm{M}$ website views per year

At BMC, research is always in progress.

Learn more biomedcentral.com/submissions 